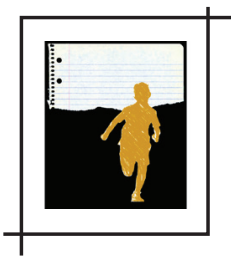

\title{
AS FESTAS JUNINAS EM TEMPO DE PANDEMIA: INTERAÇÃO E BRINCADEIRAS NA EDUCAÇÃO INFANTIL
}

\author{
Nadia Rockenback* \\ Rosemary Gonçalves de Oliveira** \\ Elaine Teresinha Dal Mas Dias***
}

Resumo: Este artigo objetiva refletir sobre as atividades práticas alinhadas aos eixos integradores interação e brincadeiras inerentes às festas juninas na educação infantil, em tempo de pandemia. Busca no Catálogo de Teses e Dissertações da Coordenação de Aperfeiçoamento de Pessoal de Nivel Superior (Capes) subsídios teóricos, a fim de entender o panorama científico a respeito das festas juninas, e aborda o contexto significativo da legislação na educação infantil que trouxesse aportes para dialogá-lo no espaço escolar restrito pelo distanciamento social. Além disso, traz algumas reflexões sobre práticas ajustadas presentes em algumas publicações aleatórias da rede social Facebook, para atender às problemáticas que cercam o contexto de afastamento das crianças, em especial as da educação infantil, da escola, em um periodo de festividade já caracterizado e instituído no calendário escolar de muitas unidades públicas e privadas. Opta pela pesquisa bibliográfica, com as abordagens metodológicas quantitativa e qualitativa, respectivamente, com o propósito de verificar o número de trabalhos encontrados e as referências epistemológicas; resulta em 15 registros totais com a busca por "festas juninas". Desses registros, foram encontrados oito títulos com o recorte do rastreio inicial, dois sem a divulgação autorizada do trabalho. Ressaltam-se as seguintes temáticas: função cultural, religiosa, política e econômica da festa junina; eixos integradores da educação infantil (interação e brincadeira); e isolamento social.

Palavras-chave: Festa junina. Educação infantil. Interação. Brincadeiras. Pandemia.

\section{INTRODUÇÃO}

A maneira como a infância é conduzida e construída contribui, significativamente, para a formação do ser humano. Nesse sentido, o desenvolvimento dentro da cultura, dos valores,

\footnotetext{
*Psicopedagoga - Doutoranda em Educação - Universidade Nove de Julho (Uninove) - E-mail: nadiarockenback@gmail.com

**Pedagoga - Doutoranda em Educação - Universidade Nove de Julho (Uninove) - E-mail: rokegi2002@yahoo.com.br

*** Doutora - Professora Titular do Programa de Pós-graduação em Educação (PPGE) - Universidade Nove de Julho (Uninove) -E-mail: elaine.mas@uni9.pro.br
} 
crenças, religião, entre outros pontos, tem papel fundamental. No Brasil atual, segundo a legislação vigente, toda criança possui direitos, e ter acesso à escola é um deles.

Dessa forma, a escola como instituição e entidade que acompanha e auxilia no processo educativo é espaço de constantes discussões e reflexões acerca do que deve ser ensinado. Ao mesmo passo, as práticas escolares, muitas vezes, trazem em si ações que reproduzem tradições e conhecimentos de um determinado povo e/ou nação, seja em nível mais amplo, como o país ou o estado, seja em nivel mais local (bairro, município). Essa formação se compõe de saberes construídos histórica e socialmente, como é o caso das festas juninas.

No periodo de pandemia, com o isolamento social, sem aulas presenciais, alunos não frequentam as escolas, mas, por orientações legais, realizam atividades escolares no contexto familiar. E, na modalidade da educação infantil, são orientados diretamente pelos familiares mais próximos do convívio.

Observando publicações aleatórias na rede social Facebook, atentou-se à infinidade de divulgação de festas juninas propostas por escolas. Uma pesquisa netnográfica', em grupo específico, posteriormente, seria muito válida, mas, por ora, a intenção é apontar algumas reflexões sobre práticas ajustadas para atender às problemáticas que cercam o contexto de afastamento das crianças, em especial as da educação infantil, da escola, em um período de festividade já caracterizado e instituído no calendário escolar de muitas unidades públicas e privadas.

Mesmo com raízes de origem religiosa, as festas são realizadas num espaço de precedência laica. No entanto, tramita o Projeto de Lei n. 943/2019² para que as festas juninas sejam reconhecidas como patrimônio cultural do Estado brasileiro.

A partir dessas inquietações, buscaram-se no Catálogo de Teses e Dissertações da Coordenação de Aperfeiçoamento de Pessoal de Nivel Superior (Capes) subsídios teóricos a fim de entender o panorama científico a respeito das festas juninas e, também, o contexto significativo da legislação na educação infantil que trouxesse aportes para dialogá-los no espaço escolar restrito pelo distanciamento social.

\section{O CAMINHO DA PESOUISA}

Com o propósito de verificar o número de trabalhos encontrados e as referências epistemológicas, foi realizada pesquisa bibliográfica, com as abordagens metodológicas quantita-

1 - Segundo Corrêa e Rozados (2017, p. 2), "Netnografia, uma ferramenta metodológica que amplia as possibilidades oferecidas pela etnografia tradicional ao permitir o estudo de objetos, fenômenos e culturas que emergem constantemente no ciberespaço a partir do desenvolvimento e da apropriação social das tecnologias da informação e da comunicação (TIC)".

2 - Disponivel em: https://www.camara.leg.br/proposicoesWeb/prop_mostrarintegra?codteor=1764523. Acesso em: 30 jun. 2020. 
tiva e qualitativa, respectivamente, de acordo com Severino (2016, p. 125): "Dai ser preferivel falar-se de abordagem quantitativa, de abordagem qualitativa, pois, com estas designações, cabe referir-se a conjuntos de metodologias, envolvendo, eventualmente, diversas referências epistemológicas".

Neste artigo, optou-se por agrupar práticas que se apresentassem disponiveis em postagens públicas aleatórias, sem, no momento, contemplar um grupo específico, a fim de observar como estão as propostas de trabalho das escolas para a educação infantil, em práticas pedagógicas desenvolvidas e divulgadas em redes sociais abertas, a julgar que as propostas, em sua maioria, estão postadas em plataformas fechadas (estados, municípios, escolas) ou em outros recursos de redes sociais pessoais de professores. Assim, buscou-se verificar se há em tais práticas a presença dos eixos fundamentais da educação infantil: interações e brincadeiras.

\section{PROCEDIMENTOS E RESULTADOS}

Para identificar os estudos referentes às festas juninas, conduzimos uma revisão de métodos mistos, no catálogo de teses e dissertações da Capes $^{3}$.

Para a procura no catálogo, utilizamos a busca por "festas juninas", nos anos de 2015 a 2019. Foram obtidos 15 registros totais resultantes. Selecionamos para análise os oito títulos que continham o recorte supracitado, e convém salientar que, embora todos os resumos encontrados estivessem disponiveis para leitura por meio do link de direcionamento, dois deles não tinham o texto na íntegra com a divulgação autorizada, fato que impossibilitou a sua utilização nesta pesquisa.

Após leitura de cada resumo das teses e dissertações encontradas, realizamos a verificação dos textos em sua íntegra, a fim de viabilizar este estudo, com o objetivo de procurar caracteristicas das festas juninas e seus fundamentos culturais e religiosos.

\section{EDUCAÇÃO INFANTIL EM TEMPOS DE PANDEMIA}

A pandemia da Covid-194 trouxe para todas as áreas da sociedade muitos desafios a serem superados. Desde a suspensão das atividades presenciais a partir do decreto de estado

\footnotetext{
3 - Pesquisa realizada nos meses de junho e julho de 2020 no Portal da Capes.

4 - "A COVID-19 é uma doença causada pelo coronavírus SARS-CoV-2, que apresenta um quadro clínico que varia de infecções assintomáticas a quadros respiratórios graves. De acordo com a Organização Mundial da Saúde, a maioria (cerca de $80 \%$ ) dos pacientes com COVID-19 podem ser assintomáticos ou oligossintomáticos (poucos sintomas), e aproximadamente 20\% dos casos detectados requerem atendimento hospitalar por apresentarem dificuldade respiratória, dos quais aproximadamente 5\% podem necessitar de suporte ventilatório" (BRASIL, 2020c).
} 
de emergência em saúde pública pelo Ministério da Saúde, no contexto educacional não foi diferente: escolas e universidades públicas e privadas suspenderam as aulas. Devido ao tempo estendido além do que se esperava inicialmente, com a obrigatoriedade do cumprimento dos dias letivos, a alternativa tomada pelos estados e municípios foi oferecer aos estudantes (sistemas público e privado) aulas a distância.

Nesse sentido, a educação infantil, com suas especificidades (crianças muito pequenas, de 0 a 3 anos de idade, e crianças pequenas, de 4 e 5 anos), categorização adotada no atual documento que orienta o trabalho pedagógico da educação infantil, a Base Nacional Comum Curricular (BNCC), é o objeto também de discussão no presente artigo.

Em 31 de dezembro de 2019, a China informa que, na cidade de Wuhan, há um surto5 por um novo vírus, da cepa dos já conhecidos coronavírus ${ }^{6}$. A Organização Mundial da Saúde (OMS) inicia um processo de monitoramento, mas já alerta ao mundo sobre a possibilidade de disseminação.

No entanto, as únicas informações divulgadas mundialmente são que a infecção se alastra com rapidez; pessoas morrem e outras se recuperam, mas nenhum remédio conhecido e testado é eficiente no tratamento; aparentemente, os idosos são mais atingidos; posteriormente, pessoas mais jovens com comorbidades apresentam fragilidades. Há tentativas de definição de grupos de risco, enquanto a OMS mantém comunicação constante com Wuhan, na China. Então, pessoas doentes com sintomas parecidos começam a aparecer em outros países, inclusive no Brasil, onde o primeiro caso confirmado e registrado aconteceu em 26 de fevereiro de 2020.

Devido à velocidade de contaminação e sem uma política de controle, orientado pela OMS, o governo determina o isolamento social e o período de quarentena por meio da Lei $n$. 13.979, de 6 de fevereiro de 2020 (BRASIL, 2020a), e, a partir dela, várias ações, como a suspensão das aulas em todos os níveis de ensino privado e público:

Art. $1^{\circ} 0$ estabelecimento de ensino de educação básica fica dispensado, em caráter excepcional, da obrigatoriedade de observância ao mínimo de dias de efetivo trabalho escolar, nos termos do disposto no inciso I do caput e no $§ 1^{\circ}$ do art. 24 e no inciso II do caput do art. 31 da Lei n 9.394, de 20 de dezembro de 1996, desde que cumprida a carga horária

\footnotetext{
5 - Em medicina, "surto acontece quando há um aumento inesperado do número de casos de determinada doença em uma região específica. Em algumas cidades, a dengue, por exemplo, é tratada como um surto e não como uma epidemia, pois acontece em regiões específicas (como um bairro)" (TELESSAÚDE SÃO PAULO, 2020).

6 - "Os coronavírus são uma grande família de vírus comuns em muitas espécies diferentes de animais, incluindo camelos, gado, gatos e morcegos. Raramente, os coronavirus que infectam animais podem infectar pessoas, como exemplo do MERS-CoV e SARS-CoV. Recentemente, em dezembro de 2019, houve a transmissão de um novo coronavírus (SARS-CoV-2), o qual foi identificado em Wuhan na China e causou a COVID-19, sendo em seguida disseminada e transmitida pessoa a pessoa" (BRASIL, 2020c).
} 
mínima anual estabelecida nos referidos dispositivos, observadas as normas a serem editadas pelos respectivos sistemas de ensino (BRASIL, 2020b).

Entretanto, com o desafio do cumprimento da carga horária mínima estabelecida pela Lei de Diretrizes e Bases da Educação Nacional (LDB) n. 9.304/1996 para a educação básica, esperava-se que o Ministério da Educação (MEC) propusesse uma reorganização dos calendários escolares em nível nacional, mas até o meio do ano letivo isso não ocorreu.

Então, fazendo jus à autonomia prevista na legislação brasileira, cada ente federativo tomou providências para garantir o cumprimento dos dias letivos ou da carga horária obrigatória com as aulas a distância.

As primeiras instituições a se organizarem foram as de ensino superior, seguidas pelas escolas privadas com a educação básica, que ofereceram o ensino a distância por meio de mídias sociais e plataformas educacionais. Muitos estados e municipios, na tentativa de equalizar a oferta de ensino, instituíram o ensino a distância também na rede pública de educação. Porém, um dos pontos de controvérsia dessa medida são as dificuldades de acesso.

Nesse aspecto, vale salientar uma discussão levantada pela Campanha Nacional pelo Direito à Educação a partir dos dados do Censo do Instituto Brasileiro de Geografia e Estatística (IBGE) do ano de 2018, a qual demonstra que 31\% dos estudantes do ensino fundamental e 42\% do ensino médio têm acesso a computador e/ou tablet; a média de casas que acessam a internet é menor que 80\%; além disso, nenhum estado tem $80 \%$ de casas com acesso à banda larga. A internet banda larga seria a ideal para os estudos a distância (CAMPANHA NACIONAL PELO DIREITO À EDUCAÇÃO, 2020). Nesse panorama, entre as muitas outras questões apontadas, destaca-se a seguinte: "0 que fazer com a educação infantil?".

O IBGE, em 2018, demonstrou que cerca de 103 mil estabelecimentos de ensino ofereciam pré-escola, atendendo 5,2 milhões de crianças de 0 a 5 anos, dos quais 23\% pertencem à rede privada (DADOS DO CENSO ESCOLAR, 2019). A Pesquisa Nacional por Amostra de Domicílios Contínua (PNADC), realizada pelo IBGE, também em 2018, aponta que 93,8\% das crianças de 4 e 5 anos de idade estavam matriculadas; as restantes $(6,2 \%)$ estavam em situação de vulnerabilidade. Na faixa etária de 0 a 3 anos, 35,6\% estavam matriculadas em creches. Na camada da população dos 25\% mais pobres do pais, 29,2\% das crianças estavam em creches; entre os 25\% mais ricos, estavam cerca de 50,8\% (OBSERVATÓRIO DO PLANO NACIONAL DE EDUCAÇÃO, 2020).

A educação infantil sempre foi um desafio desde sua origem assistencialista, quando surgiram as primeiras instituições para cuidar das crianças das familias com mães trabalhadoras nas fábricas. Segundo o Referencial Curricular Nacional para a Educação Infantil Rcnei (BRASIL, 1998, p. 17): 
0 atendimento institucional à criança pequena, no Brasil e no mundo, apresenta ao longo de sua história concepções bastante divergentes sobre sua finalidade social. Grande parte dessas instituições nasceram com o objetivo de atender exclusivamente às crianças de baixa renda. 0 uso de creches e de programas pré-escolares como estratégia para combater a pobreza e resolver problemas ligados à sobrevivência das crianças foi, durante muitos anos, justificativa para a existência de atendimentos de baixo custo, com aplicações orçamentárias insuficientes, escassez de recursos materiais; precariedade de instalações; formação insuficiente de seus profissionais e alta proporção de crianças por adulto.

Desde seu surgimento, há muito por realizar em termos de acesso, da formação do sujeito, na aprendizagem e no desenvolvimento infantil.

O Rcnei, as Diretrizes Curriculares Nacionais para a Educação Infantil (Dcnei) e, mais recentemente, a BNCC trazem como eixos fundamentais para o desenvolvimento e a aprendizagem infantil as interações e o brincar, pois consideram o que determina a Lei $n$. 9.394/1996: "Art. 29. A educação infantil, primeira etapa da educação básica, tem como finalidade o desenvolvimento integral da criança até 5 (cinco) anos de idade, em seus aspectos físico, psicológico, intelectual e social, complementando a ação da família e da comunidade" (BRASIL, 1996).

A LDB ainda aponta para a educação infantil gratuita às crianças de até 5 anos de idade e para o controle de frequência pela instituição pré-escolar, os quais são pontos de extrema importância neste momento de não presença em sala de aula, pois cria-se um abismo entre a falta de acesso às tecnologias para muitos e os nortes para o trabalho pedagógico. A frequência mínima de 60\% exigida pela lei pode ser flexibilizada em casos específicos, mas as demandas das crianças não se encerram nesse aspecto.

0 Rcnei como guia pedagógico orientador para educadores e professores que atuam com crianças pequenas e bem pequenas considera que "seu caráter não obrigatório visa a favorecer o diálogo com propostas e currículos que se constroem no cotidiano das instituições, sejam creches, pré-escolas ou nos diversos grupos de formação existentes nos diferentes sistemas (BRASIL, 1998, p. 14).

Nessa concepção, entende o papel do professor como um mediador, porque "na instituição de Educação Infantil o professor constitui-se, portanto, no parceiro mais experiente, por excelência, cuja função é propiciar e garantir um ambiente rico, prazeroso, saudável e não discriminatório de experiências educativas e sociais variadas" (BRASIL, 1998, p. 30).

As Dcnei, com o objetivo de estabelecer as diretrizes "a serem observadas na organização de propostas pedagógicas na Educação Infantil [...] para orientar as políticas públicas e a elaboração, planejamento, execução e avaliação de propostas pedagógicas e curriculares de Educação Infantil" (BRASIL, 2010, p. 11), salientam a concepção da aprendizagem da criança 
por meio de experiências de interações e de brincar: "As creches e pré-escolas, na elaboração da proposta curricular, de acordo com suas caracteristicas, identidade institucional, escolhas coletivas e particularidades pedagógicas, estabelecerão modos de integração dessas experiências" (BRASIL, 2010, p. 27).

Tendo o Rcnei e as Dcnei como referenciais básicos, a BNCC, no que concerne à educação infantil, reitera a aprendizagem por meio de experiências e eixos estruturantes nas interações e no brincar:

\begin{abstract}
[...] para que as crianças aprendam em situações nas quais possam desempenhar um papel ativo em ambientes que as convidem a vivenciar desafios e a sentirem-se provocadas a resolvê-los, nas quais possam construir significados sobre si, os outros e o mundo social e natural (BRASIL, 2017, p. 35).
\end{abstract}

Além disso, no que tange às práticas de cuidados pessoais, as brincadeiras, na experimentação de materiais variados e no contato com o outro, trazem a intencionalidade do papel do educador que abrange "a organização e proposição de experiências que permitam às crianças conhecer a si e ao outro e de conhecer e compreender as relações com a natureza, com a cultura e com a produção científica" (BRASIL, 2017, p. 34-35).

Segundo Teles (2018, p. 50), "aos poucos a educação vem sendo pensada de forma mais realista e menos impositiva". Entende-se que ainda existem muitas lacunas entre o que se determina e o que acontece na realidade, mas é crucial que se mantenham os debates acerca da educação e, especificamente, da educação infantil.

Nesse viés, alinham-se as determinações das leis e das políticas públicas em prol do desenvolvimento da criança, e atribui-se à sociedade em geral - à escola, aos professores e à família - um papel de mediação e monitoramento de cuidados e atividades planejados para atingir as necessidades de cada singularidade e as especificidade que surjam no decorrer do processo de aprendizado e coexistência.

Diante do exposto, a festa junina corresponde a um dos momentos de impacto, por sua implantação prática nas unidades escolares ao longo do tempo e seu caráter integrador entre interação e brincadeira.

\title{
O QUE DIZEM OS AUTORES SOBRE FESTAS JUNINAS
}

Neste cenário de mudanças e alternativas, a fim de atender às demandas não apenas da lei, mas das necessidades pedagógicas e sociais que não se encerram na escola, buscaram-se, na literatura científica, entendimentos do cerne das festas juninas que em muitos casos fazem parte do calendário escolar, a fim de compor este artigo. 
Quadro 1 Pesquisas abordando as festas juninas (2015-2019)

\begin{tabular}{|c|c|c|c|}
\hline \multicolumn{4}{|c|}{ Chave de busca "festa junina"/ "festejos juninos" } \\
\hline Autor/Instituição & Título da tese/Dissertação & Ano & Objetivo \\
\hline $\begin{array}{l}\text { Elielton Benedito Castro } \\
\text { Gomes } \\
\text { Universidade Federal do Pará }\end{array}$ & $\begin{array}{l}\text { Adeus Maio! Salve Junho!: } \\
\text { narrativas e representações dos } \\
\text { festejos juninos nos anos de } \\
1950\end{array}$ & 2016 & $\begin{array}{l}\text { Analisar as narrativas e } \\
\text { representações dos festejos } \\
\text { juninos do Belém do Pará nos } \\
\text { anos de } 1950 .\end{array}$ \\
\hline $\begin{array}{l}\text { Debora Odeth Leoncio de } \\
\text { Lucena } \\
\text { Universidade de Mogi das } \\
\text { Cruzes }\end{array}$ & $\begin{array}{l}\text { Folkmarketing e as politicas } \\
\text { públicas para o } \\
\text { desenvolvimento local na Festa } \\
\text { Junina de Campina Grande-PB }\end{array}$ & 2016 & $\begin{array}{l}\text { Analisar a Festa como produto } \\
\text { cultural que beneficia a cidade } \\
\text { com melhorias sociais e } \\
\text { econômicas, além do } \\
\text { desenvolvimento de diferentes } \\
\text { profissionais. }\end{array}$ \\
\hline $\begin{array}{l}\text { Glauciene Dutra Silva } \\
\text { Fundação Universidade } \\
\text { Federal de Roraima }\end{array}$ & $\begin{array}{l}\text { "O maior arraial da Amazônia": } \\
\text { um olhar geográfico sobre o } \\
\text { "patrimônio imaterial dos } \\
\text { festejos juninos", em Boa } \\
\text { Vista/RR }\end{array}$ & 2017 & $\begin{array}{l}\text { Internalizar como se projeta a } \\
\text { dinâmica das festas juninas na } \\
\text { capital de Roraima. }\end{array}$ \\
\hline $\begin{array}{l}\text { Viviane Alice de Oliveira } \\
\text { Universidade Federal do } \\
\text { Tocantins }\end{array}$ & $\begin{array}{l}\text { A História que se ensina e se } \\
\text { aprende nas comemorações } \\
\text { escolares em escolas de } \\
\text { Educação Básica em Xinguara - } \\
\text { PA: Festa Junina, Dia da } \\
\text { Independência e Dia da } \\
\text { Consciência Negra }\end{array}$ & 2018 & $\begin{array}{l}\text { Apresentar as relações entre } \\
\text { tais comemorações e o currículo } \\
\text { ensinado em sala de aula. }\end{array}$ \\
\hline $\begin{array}{l}\text { Jordania Alyne Santos } \\
\text { Marques } \\
\text { Universidade Federal do } \\
\text { Rio Grande do Norte }\end{array}$ & $\begin{array}{l}\text { As territorialidades da Festa } \\
\text { Junina de Campina Grande (PB) }\end{array}$ & 2018 & $\begin{array}{l}\text { Compreender as apropriações } \\
\text { territoriais mediadas pelas } \\
\text { práticas sociais e representações } \\
\text { subjetivas na festa junina de } \\
\text { Campina Grande, na Paraiba } \\
\text { (2016-2117). }\end{array}$ \\
\hline $\begin{array}{l}\text { Nadiel Cavalcante de Sousa } \\
\text { Universidade Federal do Rio } \\
\text { Grande do Norte }\end{array}$ & $\begin{array}{l}0 \text { corpo na Festa Junina: } \\
\text { reflexões simbólicas e estéticas } \\
\text { para a educação fisica }\end{array}$ & 2018 & $\begin{array}{l}\text { Discutir alguns significados } \\
\text { dos elementos simbólicos e } \\
\text { estéticos presentes na festa } \\
\text { junina. }\end{array}$ \\
\hline
\end{tabular}

Fonte: Elaborado pelos autores com base no catálogo de teses e dissertações da Capes.

Gomes (2016), ao analisar as narrativas e representações das festas juninas de Belém do Pará, nos anos de 1950, aponta que falar delas é trazer à tona um conjunto de práticas culturais hibridizadas, rurais e urbanas, e as referências jornalisticas e eruditas a respeito desses festejos populares da cidade. Segundo o autor, trata-se de eventos "que aproximam os indi- 
víduos da urbe, conferindo às relações de sociabilidade um estado de efervescência e, que muitas vezes, ultrapassa a vida social estabelecida" (GOMES, 2016, p. 53).

Lucena (2016, p. 25), por sua vez, analisa a

Festa como produto cultural que beneficia a cidade com melhorias sociais e econômicas, além do desenvolvimento de diferentes profissionais; a pesquisa é fundamentada nas teorias de folkmarketing e em marcos legais locais e nacionais.

Lucena (2016, p. 25) aponta também que a criação das Conferências de Cultura, "que cortaram o país no ano de 2014, resultou na criação do Sistema Nacional de Cultura, dentro do mesmo espírito da ordem sistêmica de outros ministérios brasileiros, assim como o da Saúde e da Educação, a título de exemplos".

Ao tratar dos interesses políticos em torno do patrimônio cultural, a autora afirma que não são méritos apenas das políticas nacionais de proteção e salvaguarda, porque "o sentimento de identidade justifica ações de proteção ao patrimônio das diversas comunidades como resposta ao processo de globalização", que tende a ajustar um mesmo grau de igualdade a todas as culturas a fim de "facilitar o processo de aceitação dos grupos hegemônicos" (LUCENA, 2016, p. 31).

0 aporte ao Dia da Independência e ao Dia da Consciência Negra apresentado por Oliveira (2018), com o intuito de verificar as possibilidades de aprendizado histórico em comemorações de diferentes constituições, remete não apenas às constituições religiosas da temática, mas também às políticas ou culturas em diferentes escolas.

Nesse contexto, reflete a autora sobre a influência das práticas culturais na realidade do aluno "[...] tais como os costumes regionais, as musicalidades, as expressões corporais, as festas e as comemorações. Nas práticas culturais há o envolvimento do professor e do aluno, e nelas se manifestam formas de aprender e de ensinar" (OLIVEIRA, 2018, p. 14).

Aponta a autora que as festas na Grécia eram religiosas, resplandeciam-se a música e 0 teatro, e voltavam-se aos cultos às divindades que salvaguardavam a cidade. Já em um contexto não tão remoto da nossa sociedade brasileira, nas festas era imprescindivel utilizar praças, ruas e igrejas, embora os fogos e as fogueiras fossem proibidos inicialmente pela Igreja, que os considerava "superstições" (OLIVEIRA, 2018, p. 30).

Outro aspecto relevante é que a "comida também era um dos elementos constituintes das festas, elas estavam diretamente associadas à colheita, citando como exemplo, o beiju, canjica e pamonha" (MARQUES, 2018, p. 32).

Silva (2017) explica que a festa passa a ser realizada nos espaços públicos e não mais apenas nas igrejas católicas no decorrer do tempo, porém, segundo a autora, as entidades religiosas ainda permanecem com suas homenagens, mas de forma que a Igreja Católica em Roraima realiza os arraiais em todas as comunidades nas festas de seus padroeiros, indepen- 
dentemente de ser em junho. Nesse viés, há o caráter de arrecadação de fundos, não apenas de construção ou manutenção dos templos, conforme aponta a autora, mas também com interesse sociopolítico e econômico, a fim de produzir o capital em espaços públicos.

Sousa (2018) registra que é uma manifestação sociocultural e religiosa nascida nos países europeus, visto que as alusões comemorativas rememoram os santos católicos de Portugal e que, ao contrário do sentido religioso que a Igreja Católica prega, as homenagens aos santos são realizadas em espaços abertos. Para a autora, tais festas não são "apenas reatualizadas quando as pessoas revivem os costumes sagrados dos santos, esse é também um período do ano em que se revivem memórias familiares e os aspectos tradicionais e culturais" (SOUSA, 2018, p. 17).

Observa-se que, além do caráter religioso, muito bem explicitado pelos autores, as questões sociais e econômicas também trazem reflexão sobre a organização e a proposta da festa junina. Assim, o aspecto simbólico está em todas as possibilidades de análise: "0 importante disso tudo é ainda a convicção obtida sobre as festas, e esses símbolos são essenciais para a compreensão da nossa cultura e tradição; são elementos-chave para compreendermos e refletirmos quem somos e de onde vimos" (SOUSA, 2018, p. 17).

Vale ressaltar o caráter de reinvenções e recriações, ao longo do tempo, para que as festas ganhem um suporte das mudanças das diretrizes culturais e adequações ao modelo social vigente. Neste momento de pandemia, isso também se estabelece tanto em relação ao local de realização da festa quanto no formato de apresentação das atividades características dela.

Vê-se que a característica mais marcante, que era o espaço público, se perde, provisoriamente, ao passo que se reorganiza em um espaço visualmente público, nas redes sociais, com o distanciamento físico entre as pessoas. Um lugar para fotos, alimentos e sujeitos caracterizados que refletem as festas, anteriormente apresentadas de forma presencial, com elementos simbólicos culturais e com o viés social e econômico que impactava os recursos financeiros das escolas.

\section{AS PRÁTICAS DAS FESTAS JUNINAS EM TEMPO DE PANDEMIA}

As crianças, mesmo da educação infantil, costumam ter na agenda escolar o convite para a festa da escola denominada arraial - às vezes, utilizam-se sinônimos. Neste momento de afastamento das escolas, muitas são as impossibilidades de participação. Então, para aproximar a prática das crianças e das diretrizes do calendário, muitos professores se empenharam para ofertar as festas juninas de forma remota.

Segundo dados do Instituto Nacional de Estudos e Pesquisa - Inep (DADOS DO CENSO ESCOLAR, 2019), no periodo de 2014 a 2018, as matrículas em creche cresceram 23,8\%. Só em 2018, o aumento foi de 5,3\%. 0 Brasil tem hoje 69,7 mil creches, das quais 74,8\% estão 
na zona urbana. A maioria (59,4\%) é municipal e 40,4\% são privadas, 25\% são conveniadas com estados e/ou municípios. A educação infantil como um todo, considerando creche e pré-escola, tem 8,7 milhões de alunos.

Mais inquietações se apresentam a partir disso: mesmo que as festas sigam as orientações do calendário e tenham as características semelhantes à forma anterior presencial, será que a interação de todos os pequenos, principalmente, aconteceu satisfatoriamente em relação ao acesso e ao amplo aspecto do seu desenvolvimento e sob mediação para isso?

Apesar das mudanças ocorridas dos últimos meses, com os efeitos causados pela pandemia, muitas escolas públicas e privadas mantiveram as comemorações referentes às festas juninas. Como se apontou, uma verificação aleatória nas redes sociais promoveu a reflexão sobre o tema, porque nas divulgações abertas se constataram alguns pontos que não se distinguem das festas presenciais. 0 Quadro 2, a seguir, apresenta uma visão geral do que se observou.

Quadro 2 Comparativo das práticas das festas juninas

\begin{tabular}{ll}
\multicolumn{1}{c}{$\begin{array}{c}\text { Práticas das festas juninas, na literatura } \\
\text { elencada e, comumente, nas escolas }\end{array}$} & \multicolumn{1}{c}{$\begin{array}{c}\text { Práticas visualizadas nas postagens } \\
\text { do Facebook }\end{array}$} \\
\hline Crianças caracterizadas (nas praças; na escola) & $\begin{array}{l}\text { Crianças caracterizadas (fotos ou vídeos; na casa do } \\
\text { professor; na casa do aluno) }\end{array}$ \\
\hline Decoração festiva (nas praças; na escola) & Decoração festiva (fotos ou vídeos; na casa do \\
\hline Adultos caracterizados (nas praças; na escola) & professor; na casa do aluno) \\
\hline Dança /música/quadrilha (nas praças; na escola) & professor; na casa do aluno) \\
\hline Pescaria (nas praças; na escola) & professor; na casa do aluno) \\
\hline "Correio do amor" com envio pessoalmente no & Pescaria (fotos ou vídeos; na casa do professor; na \\
decorrer da festividade & casa do aluno) \\
\hline Alimentos tipicos ofertados ou vendidos (nas & e desenhos para os colegas de sala \\
\hline cantinas, barracas; ou merenda) & Alimentos tipicos ofertados ou vendidos (fotos, \\
\hline
\end{tabular}

Fonte: Elaborado pelos autores com base nas postagens do Facebook.

A princípio, o que difere as festas são o espaço físico e a redução de pessoas em contato físico. 0 que se nota é que as atividades e a intenção ou o objetivo permaneceram. Nas redes sociais, é possível ver diversas fotos e vídeos públicos que apresentam a caracterização de crianças e adultos, inclusive com a entrega às famílias de kits para que os alunos participassem das festas. Não se sabe se todas as escolas do país seguiram esse critério devido à não 
investigação mais aprofundada no momento. Mas se observou, nas redes sociais, um fenômeno de entrega via drive-thru realizado por algumas escolas.

De acordo com Teles (2018), o currículo embasado na Teoria da Atividade Sócio-Histórico-Cultural remete-nos à reflexão sobre as atividades que promovam o desenvolvimento individual na interação com os outros e, consequentemente, com o meio sociocultural. As brincadeiras apresentadas em vídeos e fotos também são alvo da nossa observação e reflexão. Brincar com os responsáveis, longe dos amiguinhos, mas os observando pelas telas dos celulares ou do computador, de forma síncrona ou assíncrona, fez parte desse momento.

Acredita-se que, mesmo na impossibilidade de elaboração de materiais pelas professoras com o auxilio das crianças, há práticas nas aulas remotas que se aproximam da presencial, entendendo que fazer o brinquedo (por exemplo, as bandeirinhas, os balões colados ou apenas pendurá-los) é algo que, além de proporcionar a inserção no grupo participativo, seja na escola, seja no convívio familiar, faz parte do aprender infantil. Segundo Benjamin (2009, p. 92), "um simples pedacinho de madeira, uma pinha ou uma pedrinha reúnem na solidez, no monolitismo de sua matéria, uma exuberância das mais diferentes figuras".

Talvez a bandeirinha vista na tela também possa ganhar outros formatos e aguçar a criatividade da criança. Entretanto, se está apenas na tela e o responsável não conseguiu por inúmeros motivos fabricá-la com a criança, como desenvolver o corte com tesoura, para determinadas faixas etárias, a colagem ajustada, o segurar na ponta do cordão, para que este não encoste no chão, e o toque com a textura do papel? Trata-se de aspectos importantes para o desenvolvimento da escrita fina e da colaboração em grupo.

Marques (2018, p. 17) relembra que, "nas ruas onde se realizam as comemorações, é corriqueiro os moradores colocarem cadeiras em suas calçadas para acompanhar o movimento e aproveitar a ocasião para vender alimentos e bebidas".

Esse aspecto se coaduna com as orientações das receitas realizadas pela turma na cozinha da escola, agora sugeridas aos lares. Diante disso, a priori, poder-se-ia verificar a disponibilidade dos responsáveis, porque muitos estão trabalhando de forma remota também; e os recursos e alimentos em lares, muitas vezes, sem a oferta básica nesse quesito.

Entende-se o cumprimento de diretrizes e o esforço de muitos professores para que seja ajustado a todos os alunos, mas, ainda assim, nem todos terão contempladas suas peculiaridades: "Incluindo o brincar no planejamento, o docente reúne fantasia, saberes e interação, desenvolvendo um trabalho que atende às reais necessidades do aluno" (PEREIRA, 2017, p. 27).

Observou-se a pescaria, em muitas postagens, cenário elaborado pelas professoras e mostrado na tela, fotografia ou vídeo; e em casas, pelos responsáveis: "0 ato de fotografar submete aquele que está fotografando a uma série de escolhas, que envolvem desde o que será capturado pela lente, o que ficará fora dela, até a forma como ele vai estabelecer essa organização" (MACHAD0, 2017, p. 51). 
Acredita-se que o raciocínio lógico e estratégico que compõe o realizar essa brincadeira só será trabalhado se a criança a realizar. 0 desenvolvimento motor e os prêmios ganham destaque, porque os menores pegam o peixinho e o colocam na boca; outros querem entrar na piscina de bolinhas; outros desejam apenas pular de alegria. Nesse universo infantil, "as crianças formam o seu próprio mundo de coisas, um pequeno mundo inserido no grande" (BENJAMIN, 2009, p. 104).

Esse aspecto do universo infantil é corroborado por Pereira (2017, p. 27), quando afirma que, "brincando na escola, a criança torna-se capaz de 'separar' pensamentos de objetos, e a ação surge das ideias, não das coisas (como quando de um material inusitado como um graveto, por exemplo, tem-se um brinquedo, como uma varinha mágica)".

Dessa forma, a criança esforça-se para pescar o peixinho e, também, ouvir que ganhou algo. Mostra o prêmio para o colega e vibra ou chora quando ele também ganha algo. Situações necessárias para que a brincadeira seja realizada e as emoções em relação a si e ao outro sejam trabalhadas também.

Apontaram-se, até o momento, algumas mudanças por conta da pandemia que se instaurou no país e no mundo. As atividades escolares, os relacionamentos pessoais e o acesso às tecnologias, entre tantas outras inquietações pertinentes a esse contexto escolar e social, serviram-nos de guias para a busca de reflexões que promovam possiveis entendimentos e mudanças de práticas já tão engessadas.

Neste momento de afastamento social ou em sala de aula presencial, entende-se que as apostilas descoladas do contexto lúdico não cumprem em totalidade as demandas dos eixos fundamentais da educação infantil.

Quando Machado (2017, p. 25) trata das concepções de infância e das variações culturais existentes que não devem ser discutidas uniformemente, ela aponta que a "natureza da infância se traduz a partir de uma dimensão plural, composta de uma matéria nutrida pela diversidade, que sofre mudanças de acordo com as normas sociais de cada lugar".

Benjamin (2009) reflete sobre um mundo singular inserido no grande. A partir dessa noção de inclusão da criança, no universo dos adultos e nas práticas culturais que the são apresentadas, entende-se que a criança, nas atividades remotas ou não, quando ilustra o desenho para o outro, com rabiscos ou com mais firmeza nos traços, quando se visualiza na foto ou quando brinca de pescar os peixinhos com a vara improvisada, vai além das expectativas das normas ou regras da brincadeira, pois ilustra o seu cenário significativo e, em uma analogia, se entende com o artista "passando por cima do pedagogo" (BENJAMIN, 2009, p. 58).

Identificar, nas práticas que foram observadas na rede social, a presença dos eixos fundamentais da educação infantil relacionados às interações e às brincadeiras exerce o primeiro passo para o questionamento, não apenas da execução delas ou da existência de cumprimento das diretrizes pelo planejamento alinhado, mas também reflete, em sala de aula ou 
em casa, sobre os aspectos contemplados e verificados a fim de ofertar às crianças práticas que possibilitam a execução e a participação delas com mediação adequada a cada idade.

A interação e as brincadeiras com os colegas de sala e com os professores se deram de forma remota, pois o contato físico foi inviabilizado pelo distanciamento social e as atividades passaram a ser orientadas pelo professor em apostilas enviadas, vídeos e plataformas.

\section{CONSIDERAÇÕES FINAIS}

Como se percebe, está-se diante de lacunas que tanto a educação presencial como a educação a distância apresentam. A fragmentação de ações e a disjunção delas são favoráveis para que o cenário apresente a falta de acesso e direcionamentos de práticas que, por vezes, não seguem as diretrizes para a educação infantil.

Assim como o brincar na escola, para a educação infantil ainda se articula com um desafio no presencial, porque o lúdico está sendo retirado cada vez mais cedo em muitas unidades escolares, a fim de cumprir com dinâmicas de alfabetização, principalmente, muito antes do que seria apropriado para essa faixa etária. Não é de hoje que muitos pais recebem em casa tais apostilas para essa faixa escolar com atividades mecanizadas e desconexas das propostas das diretrizes nacionais e, até mesmo, dos planejamentos escolares.

Simbolicamente, infere-se que a foto do alimento apresenta a impossibilidade de todas as crianças terem acesso de forma objetiva a ele, mesmo com as tentativas de inserção nas festividades, tornando-se espectro do dia a dia em suas urgências e dinâmicas mais básicas.

Reafirma-se que, embora o brincar tenha ganhado cada vez mais relevância científica para o estudo do desenvolvimento humano, algumas atividades para as crianças denotam ainda uma mecanização de tarefas que fogem dessa dinâmica e caem na reprodução do que ainda não Ihes faz sentido.

Outro aspecto é a interação com os amigos, e o entendimento disso, nas festas remotas, pode não ter atingido a proposta, porque a criança, principalmente na educação infantil, pode não ter se apropriado do nível simbólico e significativo que the foi apresentado, porém o mesmo poderá ocorrer nas aulas presenciais se as práticas se afastarem dos objetivos dos eixos norteadores: interação e brincadeiras.

No que se refere às brincadeiras, incluindo as das festas juninas, poucos foram os feedbacks às solicitações das postagens aleatórias observadas. Assim, infere-se que nem todas as crianças participaram efetivamente das atividades. Nesse aspecto, seria um compromisso planejar, portanto, meios de acesso e que as atividades fossem idealizadas da criança para a atividade e não ao contrário.

0 que se percebe, portanto, são lacunas ainda mais evidenciadas por este momento singular de pandemia. E questiona-se a educação a distância para a educação básica em um 
país ainda tão aquém da oferta presencial, mas atenta-se também para uma preocupação ainda maior que seria o retorno às aulas neste periodo sem a cura efetiva do vírus.

Assim, apresentou-se um norte para futuras pesquisas sobre esse tema e problemáticas foram elencadas, visto que surgem e ressurgem ao longo do tempo na educação brasileira, porém, agora, há o desafio de associá-las ao momento de uma pandemia. Reafirma-se a ideia de ampliação netnográfica, em um grupo específico, posteriormente, para o construto da pesquisa em educação.

\title{
Festas juninas in time of pandemic: interaction and play in early childhood education
}

\begin{abstract}
Intend to make reflections about the practical activities aligned with the fundamental interactions and plays that are inherent of festas juninas, on pandemic times. Search available at Catálogo de Teses e Dissertações da Coordenação de Aperfeiçoamento de Pessoal de Nivel Superior (Capes) theoretical subsidies, aiming to understand the scientific overview concerning festas juninas, addressing as well the significant context of early childhood education legislation that has brought support to the school environment restrictions caused by the social distancing. Furthermore, it brings a few reflections on the adjustment of practical activities to the social media known as Facebook, as an answer to the challenges around the detachment from children to school, especially those in preschool, during a festivity time already institutionally set at the calendar of multiple private and public schools. It was chosen the bibliographical research, utilizing quantitative and qualitative methodological approaches, respectively, to verify the number of academic works and epistemological references; as a result, 15 reports were found as total when searched for festa junina. Eight reports with the initial search track were found, which two of them were published without previous permission. The themes highlighted were: a cultural, religious, political, and economic function of festas juninas; central focus early childhood education (interaction and plays); and social distancing.
\end{abstract}

Keywords: Festa junina. Early childhood education. Interaction. Plays. Pandemic.

\section{REFERÊNCIAS}

BENJAMIN, W. Reflexões: a criança, o brinquedo e a educação. São Paulo: Duas Cidades, 2009. BRASIL. Lei no 9.394, de 20 de dezembro de 1996. Estabelece as diretrizes e bases da educação nacional. Diário Oficial da União, 23 dez. 1996. Disponivel em: http://www.planalto.gov. br/ccivil_03/leis/I9394.htm. Acesso em: 12 jun. 2020.

BRASIL. Referencial Curricular Nacional para a Educação Infantil. Brasilia: Ministério da Educação e do Desporto, Secretaria de Educação Fundamental, 1998. 
BRASIL. Diretrizes Curriculares Nacionais para a Educação Infantil. Brasilia: Ministério da Educação, Secretaria de Educação Básica, 2010.

BRASIL. Base Nacional Comum Curricular. Brasilia: Ministério da Educação, Secretaria de Educação Básica, 2017. Disponível em: http://basenacionalcomum.mec.gov.br/a-base. Acesso em: 16 jun. 2020.

BRASIL. Lei n 13.979, de 6 de fevereiro de 2020. Diário Oficial da União. Brasília, DF, 7 fev. 2020a. Disponivel em: http://www.planalto.gov.br/ccivil_03/_ato2019-2022/2020/lei/L13979. htm. Acesso em: 20 jun. 2020.

BRASIL. Medida Provisória no 934, de $1^{\circ}$ de abril de 2020. Diário Oficial da União. Brasilia, DF, 1 abr. 2020b. Disponivel em: http://www.in.gov.br/en/web/dou/-/medida-provisoria-n-934-de-1-de-abril-de-2020-250710591. Acesso em: 15 jun. 2020.

BRASIL. Ministério da Saúde. Sobre a doença. 2020c. Disponivel em: https://coronavirus. saude.gov.br/sobre-a-doenca. Acesso em: 20 jun. 2020.

BRASIL. Projeto de Lei n 943, de 2019. Reconhece as Festas Juninas como manifestação da cultura nacional. Brasilia: Câmara dos Deputados, 2019. Disponivel em: https://www.camara. leg.br/proposicoesWeb/prop_mostrarintegra?codteor=1764523. Acesso em: 30 jun. 2020.

CAMPANHA NACIONAL PELO DIREITO À EDUCAÇÃO. Guia COVID-19- Volume 3: Educação a Distância. São Paulo, 2020. Disponivel em: https://campanha.org.br/acervo/guia-covid-19-educacao-distancial. Acesso em: 16 jun. 2020.

CORRÊA, M. de V.; ROZADOS, H. B. F. A netnografia como método de pesquisa em Ciência da Informação. Revista Eletrônica de Biblioteconomia e Ciência da Informação, v. 22, n. 49, p. 1-18, maio/ago. 2017. Disponivel em: https://periodicos.ufsc.br/index.php/eb/article/ view/1518-2924.2017v22n49p1/34047. Acesso em: 25 jun. 2020.

DADOS DO CENSO ESCOLAR. Número de matrículas na educação infantil cresceu 11,1\% de 2014 a 2018. Portal INEP, Brasilia - DF, 4 fev. 2019. Disponivel em: http://portal.inep.gov.br/ artigo/-lasset_publisher/B4AOV9zFY7Bv/content/dados-do-censo-escolar-numero-dematriculas-na-educacao-infantil-cresceu-11-1-de-2014-a-2018/21206. Acesso em: 10 jun. 2020.

GOMES, E. B. C. Adeus Maio! Salve Junho!: narrativas e representações dos festejos juninos nos anos de 1950. 2016. 135 f. Dissertação (Mestrado em História) - Universidade Federal do Pará, Belém, 2016.

LUCENA, D. O. L. de. Folkmarketing e as políticas públicas para o desenvolvimento local na festa junina de Campina Grande-PB. 2016. 76 f. Dissertação (Mestrado em Políticas Públicas) - Universidade de Mogi das Cruzes, Mogi das Cruzes, 2016. 
MACHADO, I. Poéticas do brincar na escola: a construção de narrativas entre imagens, palavras e crianças. 2017. 156 f. Dissertação (Mestrado em Diversidade Cultural e Inclusão Social) - Universidade Feevale, Novo Hamburgo, 2017.

MARQUES, J. A. S. As territorialidades da festa junina de Campina Grande-PB (2016-2017). 2018. 116 f. Dissertação (Mestrado em Geografia) - Universidade Federal do Rio Grande do Norte, Natal, 2018.

OBSERVATÓRIO DO PLANO NACIONAL DE EDUCAÇÃO. Educação infantil. 2020. Disponivel em: https://www.observatoriodopne.org.br/indicadores/metas/1-educacao-infantil/indicadores/ porcentagem-de-criancas-de-0-a-3-anos-na-educacao-infantil/. Acesso em: 19 jun. 2020.

OLIVEIRA, V. A. de. A história que se ensina e se aprende nas comemorações escolares em escolas de educação básica em Xinguara - PA: festa junina, Dia da Independência e Dia da Consciência Negra. 2018. 119 f. Dissertação (Mestrado em Ensino de História Instituição de Ensino) - Universidade Federal do Tocantins, Araguaína, 2018.

PEREIRA, M. R. Infância brincante: narrativas de crianças de terceiro ano de uma escola pública estadual sobre o brincar na escola. 2017. 93 f. Dissertação (Mestrado em Educação e Tecnologia) - Instituto Federal de Educação, Ciência e Tecnologia Sul-rio-grandense, Pelotas, 2017.

SEVERINO, A. J. Metodologia do trabalho científico. São Paulo: Cortez, 2016.

SILVA, G. D. "O maior arraial da Amazônia": um olhar geográfico sobre o "patrimônio imaterial dos festejos juninos", em Boa Vista/RR. 2017. 180 f. Dissertação (Mestrado em Sociedade e Fronteiras) - Fundação Universidade Federal de Roraima, Boa Vista, 2017.

SOUSA, N. C. de. 0 corpo na festa junina: reflexões simbólicas e estéticas para a Educação Física. 2018. Dissertação (Mestrado em Educação Física) - Universidade Federal do Rio Grande do Norte, Natal, 2018.

TELES, F. P. O brincar na educação infantil com base em atividades sociais, por um currículo não encapsulado. 2018. 216 f. Tese (Doutorado em Linguistica Aplicada e Estudos da Linguagem) - Pontifícia Universidade Católica de São Paulo, São Paulo, 2018.

TELESSAÚDE SÃO PAULO. Qual é a diferença entre surto, epidemia, endemia, pandemia e sindemia? São Paulo, 16 dez. 2020. Disponível em: https://www.telessaude.unifesp.br/index. php/dno/redes-sociais/159-qual-e-a-diferenca-entre-surto-epidemia-pandemia-e-endemia. Acesso em: 20 jun. 2020. 